\title{
PolítICA tURística ANTE el COVID-19: el CASO de MéXICO
}

\author{
AlFONSO ZePEDA ARCE \\ alfonso.zepeda@academicos.udg.mx \\ LORENA TRINIDAD MEDINA ESPARZA \\ lorena.medina@academicos.udg.mx \\ ANA MARÍA FLORES IBARRA \\ ana.fibarra@academicos.udg.mx \\ Centro Universitario de la Costa Sur, Universidad de Guadalajara, Jalisco, México
}

Dado que el turismo a nivel mundial enfrenta un desafío quizás nunca visto, el objetivo del presente trabajo es aportar elementos de análisis para la discusión referente a las políticas implementadas en México ante el COVID-19. Se desarrolló bajo el enfoque de investigación exploratoria, con la revisión de políticas públicas en respuesta a la pandemia e impacto en el turismo, enumeradas y enfrentadas a las recomendaciones de organismos internacionales; se utilizó parte de la metodología de estudios de reparación de imagen durante crisis en el sector, relacionando eventos disruptivos y turismo que afectaron en el pasado. Se concluye que hasta junio de 2020 el mundo sigue tambaleante, es una nueva crisis con un futuro incierto, empero, en México se ha reconsiderado al turismo como una actividad esencial, por ello será necesaria una gran dosis de ímpetu para potenciar esta actividad. Es fundamental que se actue con compromiso, responsabilidad y solidaridad.

Palabras clave: México, COVID-19, pandemia, turismo, políticas.

\section{TOURISM POLICY IN THE FACE OF COVID-19: THE CASE OF MEXICO}

Given that tourism worldwide faces a challenge perhaps never seen before, the objective of this document is to provide elements of analysis for the discussion regarding the policies implemented in Mexico in the face of COVID-19. Was developed under the exploratory research approach, public policies in response to the pandemic and impact on tourism, reviewed, listed and compared with the recommendations of international organizations. Part of the methodology of image repair studies was used during crisis in the sector, disruptive events and tourism that affected in the past were related. It is concluded that, until June 2020, the world is still reeling, it is a new crisis with an uncertain future, however, in Mexico tourism has been reconsidered as an essential activity, for this reason a large dose of impetus will be necessary to enhance this activity. It is essential to act with commitment, responsibility and solidarity.

Keywords: Mexico, COVID-19, pandemic, tourism, policies.

Fecha de recepción: 28 de junio de 2020 Fecha de aceptación: 28 de agosto de 2020.

CÓMO CITAR: Zepeda, A., Medina, L. y Flores, A. (2020). Política turística ante el COVID-19: el caso de México. Dimensiones Turísticas [Número especial: Turismo y COVID-19], 4, 69-94. https://doi.org/10.47557/WOXQ7908 


\section{Introducción}

- I turismo a nivel mundial enfrenta un desafío quizás nunca visto. Desde los primeros meses de 2020, de manera abrupta, los destinos turísticos y centros recreacionales fueron cerrados por motivos de la pandemia del coronavirus o COVID-19, provocando la cancelación de miles de vuelos, de reservaciones en hoteles, y de los servicios que de manera directa e indirecta participan y han sufrido el paro de actividades.

México no ha sido la excepción, las afectaciones son considerables, tanto por ser un sector importante en la economía del país, como por la decisión del gobierno de considerar la actividad turística como una de las actividades no esenciales, en principio, calificándola como un medio de propagación del virus y, por ende, de contagios, toda vez que las personas requieren desplazarse de su lugar de origen al destino elegido para visitar.

Por lo tanto, las organizaciones, los gobiernos y las distintas instituciones alrededor del orbe, han tenido que implementar diversas acciones, estrategias y políticas para enfrentar la pandemia, pensando en una nueva normalidad para la humanidad.

El trabajo comienza con los antecedentes y marco del COVID-19, eventos disruptivos que han afectado el turismo, incluyendo una caracterización de la pandemia debido a sus particularidades especiales; después, se revisa la coherencia de las recomendaciones de los organismos internacionales, encontrando un acercamiento a ellas. Por último, se enlistan las actuaciones en materia política implementadas por México, contra los indicadores de las políticas internacionales, para tener un acercamiento de su efectividad.

\subsection{Planteamiento del problema}

En México ha sido evidente la ausencia de planteamientos integrales para hacer frente a la pandemia de COVID -19 y su afectación al sector turismo. Lo anterior se ve reflejado en las políticas públicas, así como en la necesidad de contar con elementos de análisis que alimenten la discusión, sumándole lo realizado en materia turística, de manera que permitan establecer una ruta de actuación hacia el futuro y aporten una revisión de lo emprendido, contrastando las acciones mexicanas frente a organismos internacionales. 


\section{Antecedentes}

La Organización Mundial de la Salud (OMS) fue notificada el 31 de diciembre de 2019 sobre el brote de enfermedad por coronavirus en Wuhan (OMS, 2020a). De acuerdo con la Organización Panamericana de la Salud (OPS), el 30 de enero se declaró la pandemia, como resultado de la dispersión de la enfermedad entre diversos países, con la correspondiente afectación a un mayor número de personas, en una emergencia generalizada (OPS, 2020).

El Síndrome respiratorio agudo severo (SARS-CoV-2) o COVID-19 se caracteriza por la aceleración en que los síntomas aparecen y su riesgo, además de los conflictos sociales y económicos que provoca (OMS, 2020b). Una pandemia se define como tal, cuando se da un aumento muy rápido e inesperado de contagios en un periodo de tiempo corto alrededor del mundo (Guardia, 2020), sus efectos a nivel internacional se reflejan en una crisis sanitaria, humana y económica (CEPAL, 2020).

Dolnicar y Zare (2020) califican al coronavirus como un impacto económico, entendiendo este, según Chappelow (2019), como las modificaciones que las relaciones macroeconómicas sufren, repercutiendo en situaciones como la pérdida de empleos y la disminución del consumo. El impacto hasta ahora visto por las afectaciones del COVID-19 se da en todos los aspectos de la vida, el trabajo, la escuela y por supuesto el turismo.

La industria turística, de acuerdo con Andreu et al. (2020) es un sector volátil que en condiciones favorables goza de un comportamiento fuerte, pero bajo malas condiciones su desarrollo desciende peligrosamente a un promedio menor que el resto de los sectores. Así, el turismo es muy sensible a las medidas para contrarrestar esta pandemia, producto de la movilidad limitada y el distanciamiento social. De acuerdo con la Asociación Española de Expertos Científicos en Turismo (AECIT, 2020), los diferentes indicadores de esta actividad, como el gasto, el flujo de visitantes, la ocupación hotelera, así como la generación de empleo directo e indirecto, prácticamente se han desplomado

Por su parte, Romero et al. (2020) señalan que el turismo masivo se ve particularmente perjudicado, al depender de la movilidad, la interacción personal y la cercanía social, debido a ello, se está en condiciones de hablar de un antes y un después para el sector turístico, así como de nuevas normalidades en él. 
Las actuaciones realizadas en materia de políticas públicas por parte de los gobiernos, las acciones planteadas por parte de las empresas y su cultura organizacional (manejo de crisis), son trascendentales para el desarrollo del sector, tanto en el presente (debido a la alta presión por su supervivencia a corto plazo) y su futuro en la recuperación del turismo, en lo que algunos investigadores han denominado "el día después", obligando a la reflexión y repensar el desarrollo de la actividad turística (Vargas, 2020).

La política pública se asume como aquel "conjunto de acciones intencionales y causas, orientadas a la realización de un objetivo de interés/beneficio público, cuyos lineamientos de acción, agentes, instrumentos, procedimientos y recursos se producen de manera constante y coherente" (Aguilar y Lima, 2009, p. 3). La Organización Mundial del Turismo (OMT, 2020a) con fecha del 28 de abril, señaló que la totalidad de los destinos habían establecido limitantes para viajar a causa del COVID-19, especificando que tal acontecimiento nunca había sido registrado en la historia, refiriendo a los 180 destinos más reconocidos.

Las afectaciones en el sector son de consideración ya que existen pérdidas diarias; por ejemplo, aquellas utilidades por habitaciones no utilizadas no pueden recuperarse después (Gössling et al., 2020). Este freno forzado del turismo, también llamado hibernación (Romero et al., 2020), en el caso de México es de grave consecuencias, ya que es considerado un sector estratégico para el país, correspondiendo al 8.7\% del Producto Interno Bruto (PIB) nacional, lo que se traduce en 4.3 millones de empleos directos y un consumo de 3.3 billones de pesos (CNET, 2020). Por otra parte, de acuerdo con los Censos Económicos de 2014 (INEGl, 2015), el 93\% de las empresas turísticas (450 mil unidades), son pequeñas y medianas empresas (Pymes) que cuentan entre dos y 10 empleos, las cuales, al ver limitadas sus ganancias, encontrarán dificultades para resolver sus responsabilidades (Madrid, 2020).

\subsection{Eventos disruptivos de salud que afectaron el turismo en el pasado}

En la historia moderna del turismo han existido diversos eventos que han afectado su desarrollo y crecimiento; en 2003, más de 8 mil humanos infectados y 900 muertes se dieron a causa del Síndrome respiratorio agudo severo (SARS), el cual produjo afectaciones en la economía y fue considerada la primera enfermedad surgida en el siglo XXI, de acuerdo con la OMS (2005). El 21 de abril de 2009, el Centro para el Control y la Prevención de Enfermedades (CDC) en los Estados Unidos de América informó acerca del recién identificado virus de la influenza AH1N1. En el caso de 
México, el 23 de abril se dio a conocer a la población la presencia del nuevo virus y se anunció la suspensión de clases de todos los niveles educativos (Cenaprece, s.f.).

Con lo anterior, se dio el cierre de diversos establecimientos, en particular aquellos con alta afluencia y espacios masivos como zonas arqueológicas, salas de cine, teatros y restaurantes, así como la emisión de recomendaciones de diversos gobiernos que exhortaron a sus ciudadanos a no viajar a México, además de tener en aislamiento a ciudadanos mexicanos que se encontraban en otros países. Esto significó afectaciones a la imagen del destino, por considerarse un foco de infección (García et al., 2009). Los costos de esa pandemia significaron aproximadamente el $1 \%$ del PIB de 2008 para el país, es decir, más de 9 millones de dólares (OPS, 2010).

En 2012 surge el Síndrome respiratorio del Medio Oriente (MERS), enfermedad provocada por un coronavirus, que pertenece a una extensa familia de virus y que para mediados de 2015 había afectado a mil 185 personas, de las cuales falleció el 37\% (OPS, 2015).

En 2014, el continente africano padeció una epidemia del virus Ébola, que contabilizó más de 28 mil 600 casos, con un porcentaje de mortalidad del 39\%, generando gastos por 53 mil millones (Guardia, 2020). Asimismo, se estima que el virus del Zika (transmitido por la picadura del mosquito Aedes aegpty). tan solo en el lapso de dos años (de 2015 a 2017) provocando un impacto negativo en el PIB estimado entre 7 mil y 18 mil millones de dólares (PNUD, 2017), lo que la ubica como emergencia sanitaria internacional.

Por su parte, el dengue también es una enfermedad de grandes números, con datos entre los 50 y 100 millones de personas anualmente, lo cual representa un impacto considerable para la economía y los sistemas de salud de los países que puede contabilizarse en una cifra cercana a los mil 800 millones por año, de acuerdo con los investigadores de la Universidad Brandeis en Estados Unidos (BBC, 2009).

En la historia reciente de México se destacan tres fenómenos que han afectado directamente el desarrollo de la actividad turística: a) los impactos del 11 de septiembre de 2001, b) los daños causados por el Huracán Wilma en octubre de 2005, y c) la contingencia epidemiológica de influenza AH1N1 en 2009 (Sectur, 2020a); esta última, como se había mencionado, provocó una serie de estragos, en respuesta a lo cual se creó el Consejo de Promoción Turística de México (CPTM, hoy extinto) y se destinó una inversión de 400 millones de pesos en la campaña Vive México, con un costo de 8 mil millones de dólares (Quiroz, 2019). 


\subsection{Una caracterización necesaria de la pandemia}

Es importante realizar algunas reflexiones respecto al desarrollo de esta pandemia, poniendo en consideración el fenómeno de la globalización, que incide en los procesos económicos y culturales en tiempo real (Castells, 2020). Recordando que la referida globalización y su entorno son producto de la política neoliberal y que las nuevas tecnologías reducen el espacio y han dado forma al mundo que hoy conocemos (Niewiadomski, 2020).

El turismo es una expresión del sistema, el cual sienta sus bases en el pensamiento desarrollista, bajo un enfoque economicista fuertemente vinculado con la evolución de la economía global, sin límites tanto de expansión como de crecimiento (Romero et al., 2020); a la par, se encuentra la marcada globalidad de esta pandemia, en un mundo interdependiente y con múltiples interconexiones, donde ya no solo nos enfrentamos a una crisis sanitaria, sino también económica (Vargas, 2020).

Así, estamos viviendo un fenómeno inédito, esta inestabilidad se encuentra caracterizada por una afectación en múltiples escenarios, una fuerte incertidumbre y recetarios de ayuda a corto plazo. Algunos gobiernos han implementado diversas acciones, imponiendo medidas reactivas y de recuperación inmediatas (Romero et al., 2020). Otros han quedado tan evidenciados por su debilidad que intentaron usar la fuerza y mandatos oficiales para la contención de la enfermedad, en sociedades cuyas desigualdades quedaron expuestas (César, 2020).

Estos desempeños diferenciados gubernamentales han abierto la posibilidad del resurgimiento en algunas partes del mundo del estado nación, de acuerdo con Niewiadomski (2020). En este marco, Boyer (2020) señala que en el pasado las crisis financieras eran producto de cuestiones atribuibles al propio entorno económico interno y en esta ocasión resulta ser provocada por un evento externo, ajeno.

Otra característica no vista con anterioridad ha sido que el inicio, la difusión y las primeras repercusiones del virus han surgido en los países de primer mundo, no mostrando (en apariencia) una relación directa con la pobreza; sin embargo, en los impactos posteriores se ha confirmado que los grupos vulnerables sí son los más afectados, como la comunidad latina en Nueva York, que representó el 35\% de los fallecidos (César, 2020). 
Igualmente, se plantean los procesos de desglobalización temporal, al verse limitados los viajes y haber un mayor control y restricciones en las fronteras, lo cual ofrece una posibilidad sin precedentes de un reinicio para la implementación y desarrollo del sector turístico, bajo los principios de la sostenibilidad (Niewiadomski, 2020), de ahí la importancia de revisar las políticas impulsadas por el gobierno de México para enfrentar el COVID-19.

\subsection{Estudios similares}

Como investigaciones de referencia en materia de salud se destaca lo realizado por la OPS y la OMS, en conjunto con la Secretaría de Integración Turística Centroamericana, las cuales desarrollaron en el año 2011 el documento Salud y turismo para Centroamérica y República Dominicana, compuesto por un manual y un programa de sensibilización (Funes, 2011). En particular sobre el COVID-19, a pesar de su inmediatez y que se encuentra en pleno desarrollo, existen varios textos entre los cuales destaca el del Global Web Index (2020), en torno al comportamiento del consumidor y sus cambios como consecuencia de la pandemia, y el de la AECIT (2020), que publicó el libro: turismo post COVID-19. El turismo después de la pandemia global. Análisis, perspectivas y vías de recuperación.

También se revisó el trabajo de 5 mil 800 Pymes norteamericanas y su impacto tras el COVID, de Bartik et al. (2020); otro documento fue el estudio de la isla de Bintan (Indonesia) y el COVID-19, de Dinarto et al. (2020); asimismo, se consultó la Revisión de enfermedades infecciosas y el turismo en peligro por su dependencia de la movilidad humana, de Yang et al. (2020); la Estrategia de recuperación de COVID-19 para la industria del turismo, de Strielkowski (2020); además del documento realizado por el Centro de Investigación y Competitividad Turística (Cicotur), denominado Estimación del impacto a la actividad turística en México: del dato al relato en el turismo, donde se plantea una serie de afectaciones al sector (Madrid, 2020); El COVID-19, de la globalización temporal a un redescubrimiento del turismo, de Niewiadomski (2020) y, finalmente, el análisis de Las iniciativas de ayuda a los estados de la Unión Europea, de Nissen y Rivas (2020).

\section{Metodología}

El presente trabajo se desarrolla bajo el enfoque de investigación exploratoria, como una forma de acercamiento al objeto de estudio. Se aplicó el método ana- 
lítico sintético para la revisión de la literatura especializada, particularmente sobre turismo en conjunto con crisis, salud y COVID-19. La búsqueda de información se centró en las principales bases de datos: Dialnet, Redalyc, Scielo, Scopus, Science y Latindex, entre otras; para su clasificación se recurrió a la metodología de pasos múltiples, con una detallada revisión de informes de órganos oficiales. Además, se analizaron estudios de casos y eventos disruptivos que han afectado al sector.

Se revisaron conceptos como políticas públicas y pandemia, lo que permitió tener un acercamiento al estado del arte. El siguiente paso fue medir la coherencia de las propuestas de organismos internacionales con el actuar de México, para determinar su acercamiento o lejanía, mediante un cuadro. Por último, se enlistaron las principales políticas implementadas por el gobierno federal y se contrastaron con los indicadores de políticas propuestos por la CEPAL (2011) con el fin de tener un acercamiento a su grado de efectividad, aplicando los preceptos de evaluación de una política pública, el cual se mide según la etapa de intervención: ex ante (previa), procesos (durante), y ex post (finalizada).

Se señala que se está en la etapa de procesos, utilizando los indicadores que se manejan para tales fines, como son: "productos (cantidad, calidad, costos), eficiencia (producto-costo), productividad (producto-insumo), logro de objetivos (resultados intermedios y finales), efectividad (contribución), y costo-efectividad (resultados)" (CEPAL, 2011, p. 36).

Una vez contrastados, mediante un semáforo se clasificaron en rojo los que se consideraron como no aceptable, amarillo como regularmente aceptable y verde aceptable, este ejercicio permitió obtener como resultado la cualificación de las acciones implementadas y un panorama situacional de la política pública ante el COVID-19 y el turismo.

\section{Resultados}

\subsection{Recomendaciones de organismos internacionales}

A nivel internacional diversos organismos han sugerido una serie de acciones y políticas públicas a implementar por los gobiernos del mundo, que inciden directa e indirectamente en el turismo, a continuación, se presenta una breve síntesis de sus propuestas: 


\section{Organización Mundial de la Salud (OMS)}

Este organismo ha difundido un cúmulo de comunicados respecto a las recomendaciones para el cuidado de la salud, sintomatologías y el desarrollo de la pandemia, creando un fondo de respuestas. En este marco, y en lo referente al turismo, en un primer momento (el 10 de enero) emitió el documento Consejos de la OMS sobre viajes internacionales y comercio, en el cual recomienda mantener la distancia entre individuos, el lavado frecuente de manos y evitar la cercanía con mascotas; en materia de sugerencias a los gobiernos se destaca la importancia de participar a los viajantes las condiciones sanitarias (OMS, 2020b).

También publicó el texto denominado Actualización de la estrategia frente al COVID-19 (OMS, 2020b), donde se conmina a las naciones a unirse para dar respuesta a la pandemia, con liderazgo, buscando empoderar a las personas a través de un constante flujo de información, enseñanza, colaboración y apoyo mutuo, además de llamar a la integración de los sectores para la contención de la enfermedad, reduciendo la transmisión y, consecuentemente, el número de fallecimientos, con énfasis en el desarrollo de vacunas y tratamientos.

\section{Organización Internacional del Trabajo (OIT)}

En marzo, la OIT manifestó a través de su presidente, Refiloe Litjobo, que las dimensiones humanas de la pandemia del COVID-19 exceden con creces el ámbito de la respuesta sanitaria. "Todos los aspectos de nuestro futuro se verán afectados", indicó y, al respecto de las políticas, mencionó lo imperioso de aplicar políticas "fiscales y monetarias expansivas sin precedentes para evitar que la actual caída precipitada, no se convierta en una recesión prolongada" (Litjobo, citado en Rider, 2020, párr. 3).

\section{Organización Mundial de Turismo (OMT)}

La OMT creó un apartado especial en su portal, el cual denominó COVID-19 Respuesta, con el propósito de brindar apoyo al sector, a la comunidad internacional y a los gobiernos. Ha emitido una serie de recomendaciones en tres ámbitos: a) gestión de la crisis y atenuación de efectos, b) generación de estímulos hacia la recuperación, y c) preparación para el futuro (OMT, 2020b).

Asimismo, en el documento Principales protocolos globales para la nueva normalidad, publicado en mayo de 2020, se reafirma la exigencia de que la industria y los gobiernos puedan apoyarse con miras a desarrollar reglas respecto a los viajes 
transfronterizos, con ayudas enfocadas en estimular la demanda, a través de incentivos fiscales, la reducción de impuestos, tasas y cargos, así como la mercadotecnia de los destinos (OMT, 2020c).

\section{World Travel \& Tourism Council (WTTC)}

El World Travel \& Tourism Council (Consejo de Viajes y Turismo) ha implementado una serie de acciones mediante su página de internet con la construcción de un micrositio dedicado al COVID-19; además, ha emitido comunicados al respecto, de los cuales se destaca el punto donde insta a los gobiernos a adoptar medidas que garanticen la supervivencia del sector, con una perspectiva humanitaria ante las personas en riesgo. De igual manera, propuso tres medidas preponderantes: a) brindar esquemas financieros que protejan los ingresos de los trabajadores, b) otorgamiento de préstamos ilimitados y sin intereses a las empresas del ramo, y c) exentar hasta por un año el pago de impuestos al sector (WTTC, 2020).

\section{Grupo Banco Mundial (GBM)}

El Banco Mundial comunicó que sus acciones emergentes destinadas al combate del COVID-19 han alcanzado a 100 países en desarrollo, con apoyos como préstamos, donativos, suspensión de deuda y otras inversiones, con el objetivo de beneficiar a la población vulnerable, robustecer los sistemas de salud y favorecer las condiciones de apoyo en torno a lo laboral (GBM, 2020).

\section{Organización de Aviación Civil Internacional (OACI)}

En marzo, esta organización adoptó la declaración sobre el COVID-19, destacando la necesidad de disminuir el riesgo sanitario. Entre los elementos expuestos se destaca la solicitud de promover e impulsar una cultura de colaboración entre las autoridades de salud pública y de aviación civil, también sugiere implementar medidas para la sostenibilidad del transporte aéreo y el más alto nivel de seguridad operacional $(\mathrm{OACl}, 2020)$.

\section{Organización para la Cooperación y el Desarrollo Económico (OCDE)}

En cuanto a la crisis, en sus múltiples vertientes (sanitaria, económica y social), la OCDE pide promover la colaboración en acciones conjuntas, así como la coordinación en materia de políticas. De tal manera, esta organización ha venido reuniendo 
datos, análisis y recomendaciones. En ese sentido se destacan las políticas en materia de salud, educación e impuestos (OCDE, 2020).

\section{Comisión Económica para América Latina (CEPAL)}

En abril de 2020, la CEPAL realizó el informe especial COVID-19, efectos económicos y sociales, en el cual se destacan algunas precisiones, se resalta que: a) la economía mundial se enfrenta a una crisis nunca vista, en salud y economía, b) el Estado debe generar condiciones para la sustentabilidad y estímulo a la economía, c) los gobiernos están actuando a prueba y error. Adicionalmente, se destacan las recomendaciones en materia de política: a) estímulos fiscales para servicios sanitarios, así como protección laboral, b) estrategias de apoyo a poblaciones vulnerables, c) aseguramiento de liquidez del sistema bancario, d) cooperación internacional y entre organizaciones, y e) eliminación de penalizaciones (CEPAL, 2020, p. 13).

Bajo este marco, se identifican y enlistan los ámbitos de actuación sugeridos por los organismos internacionales, contrastados con lo realizado por México, en sintonía de cada acción.

Tabla 1. Acciones por área del gobierno federal versus recomendaciones de organismos internacionales

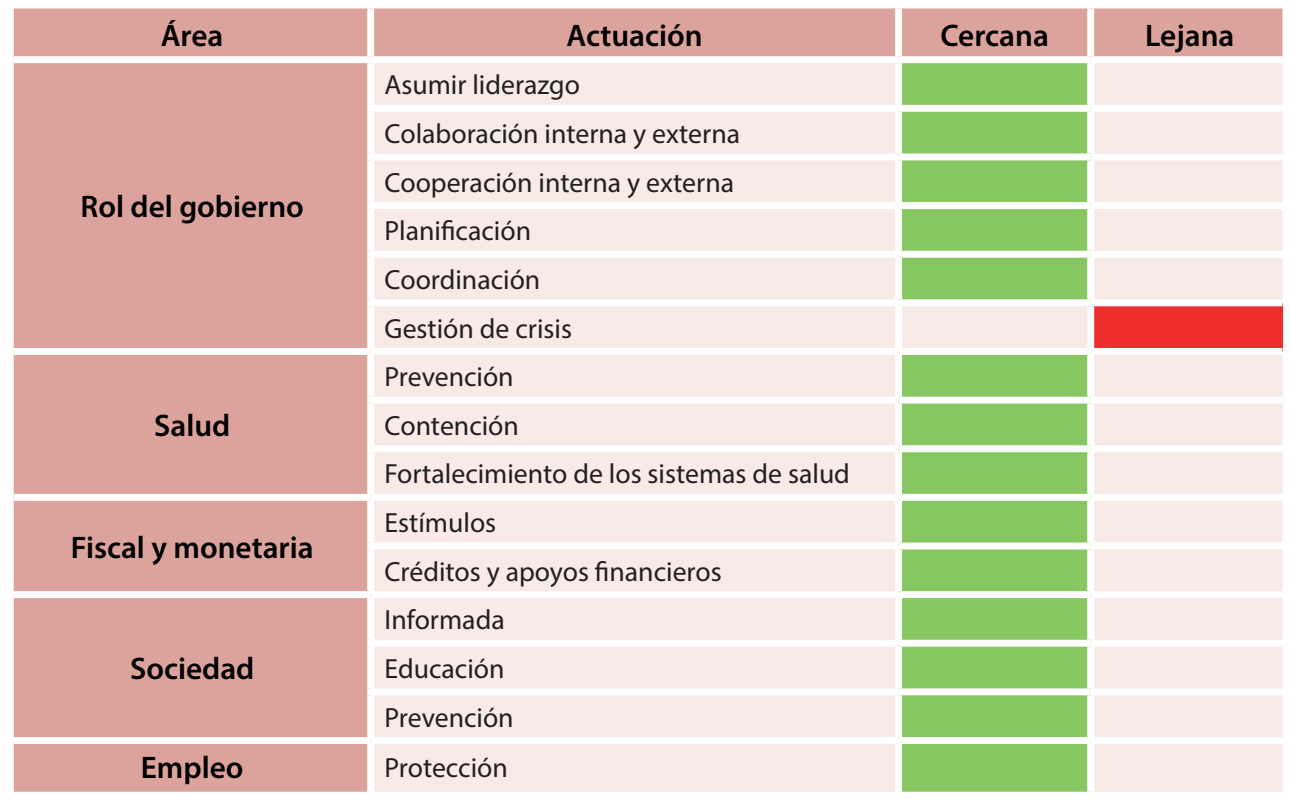

Fuente: Elaboración propia. 


\subsection{Políticas establecidas en México}

Existen algunos antecedentes en materia política, generados con el propósito de disminuir el número de casos, así como el porcentaje de fallecimientos, atendiendo las afectaciones asociadas, tanto en lo social como en lo económico, los cuales ofrecen protocolos de actuación, de preparación y de respuesta, se destacan entre ellos el Plan nacional de preparación y respuesta ante una pandemia de influenza, publicado en 2006; el Programa operativo nacional de respuesta ante una pandemia de influenza AH1N1, de 2009; el Plan nacional para la preparación y respuesta ante la intensificación de la influenza estacional o ante una pandemia de influenza; y la Estrategia de control de vectores en el escenario de transmisión simultánea de dengue, todos ellos creados por el Centro Nacional de Programas Preventivos y Control de Enfermedades (Cenaprece, s.f.).

Aunado a ello, se tienen registradas las lecciones aprendidas de los acontecimientos de 2009, que están directamente relacionadas con las políticas públicas, tales como impulsar la organización entre los tomadores de decisiones y la academia para el trabajo colaborativo, a la par de la colaboración entre diversos sectores para la elaboración de protocolos. Asimismo, el Cenaprece (s.f) establece la necesidad de trabajar en esquemas preventivos, objetivos que, en cierta medida, sí se cumplieron.

\section{Medidas generales ante el COVID-19}

El 16 de marzo, la Secretaría de Educación Pública inició de manera oficial la suspensión de actividades a nivel pregrado, llevando a los medios de comunicación los contenidos educativos. Un día después suspendió actividades la Universidad Nacional Autónoma de México (UNAM) y le siguieron el resto de las Instituciones de Educación Superior (IES) del país. El 23 de marzo, la Administración Pública implementó en sus empleados federales el trabajo desde casa, para el caso de trabajadores vulnerables y padres con hijos menores de 12 años, días laborales alternativos para la atención del público, y entradas escalonadas.

La Fase 2 de la pandemia se decretó el 24 de marzo; además, inició la Jornada nacional de sana distancia (Susana distancia), promoviendo medidas de higiene básicas, distanciamiento social, suspensión de actividades no esenciales e invitando a los ciudadanos a quedarse en casa. El Presidente de la República, Andrés Manuel López Obrador, el 28 de marzo hizo un llamado al sector privado a unirse a las medidas tomadas, con énfasis en mantenerse en los hogares y no salir, solo en caso de realizar actividades esenciales. 
El Consejo de salud pública declaró emergencia sanitaria el 30 de marzo, interrumpiendo las actividades no esenciales. Únicamente los servicios médicos, sanitarios, seguridad pública y otras actividades esenciales se mantuvieron en acción; en el caso de adultos mayores y personas vulnerables en general, se ordenó observar el ya reconocido "quédate en casa". A la par, el 31 de marzo se signó el Acuerdo de gobernabilidad y unidad nacional para la lucha contra el COVID-19, por parte de los gobiernos federal y estatales.

Inicia la Fase 3 de la pandemia el 20 de abril (OCDE, 2020). El 14 de mayo se establece un semáforo por regiones, con una estrategia para la puesta en marcha de actividades sociales, educativas y económicas, de forma sistemática y regulada (DOF, 2020c), dividido en tres etapas:

a) Etapa 1. Inicia el 18 de mayo, con reapertura en municipios sin casos de COVID-19.

b) Etapa 2. Del 18 al 31 de mayo, con la elaboración de protocolos sanitarios para el reinicio seguro de actividades.

c) Etapa 3. A partir del 1 de junio, se reanudan las actividades sociales, educativas y económicas, de acuerdo con el semáforo por regiones. El 17 de mayo se anunció el Plan de regreso a la nueva normalidad (SELA, 2020).

\section{Medidas sobre el sector turístico}

Es importante señalar que, hasta el 25 de abril, el Estado no había emitido restricción alguna en cuanto al traslado de los ciudadanos extranjeros, solo se solicitaba el llenado de un cuestionario de la Secretaría de Salud. México y Estados Unidos realizaron acuerdos en cuanto a sus movimientos fronterizos no esenciales y Guatemala cerró su frontera con México. Belice mantuvo habilitado únicamente el cruce de mercancías con el país.

A inicios de marzo, la Asociación de Secretarios de Turismo de México tomó la medida de la suspensión temporal de la temporada de cruceros (César, 2020); el 8 de abril el Secretario de Turismo, Miguel Torruco, ante secretarios de turismo estatales y organizaciones del ramo presentó la Estrategia digital para la contención de crisis del sector turístico, la cual está pensada en tres fases: a) inmediata - con el mensaje "nos vemos pronto", destinada a contener la crisis, b) intermedia - usando la frase "el viaje está dentro de nosotros", con el objetivo de generar acompañamiento, y c) de recuperación - "México te necesita", dirigida tanto a la venta dura en el mercado 
internacional (16 puntos estratégicos), como al doméstico, y abarca todos los segmentos (Sectur, 2020d, párr. 13).

El 23 de abril, la Secretaría de Turismo y la Secretaría de Salud emitieron la Actualización del protocolo de atención a personas en centros de hospedaje y restaurantes durante la cuarentena obligatoria por COVID-19, en ella establecen las medidas sanitarias que los establecimientos deben aplicar y los procedimientos de desinfección y mantenimiento (Sectur, 2020c). Adicionalmente, el Instituto Nacional de Migración ordenó el 26 de abril la salida de extranjeros que se encontraban en alojamientos y estaciones migratorias (OCDE, 2020).

El 20 de mayo, la Secretaría de Turismo en conjunto con la Secretaría de Salud emitieron los Lineamientos nacionales para la reapertura del sector turístico, con el propósito de establecer acciones de prevención y disminución de los riesgos de contagio, las acciones de cumplimiento son: a) limpieza y desinfección de superficies y objetos de uso común, b) lavado correcto de manos, c) filtros sanitarios, d) capacitación al personal de las empresas, e) uso de equipo de protección personal; además, se especifican los rubros para cada tipo de empresa, señalándose medidas para el regreso a las labores, estrategias de comunicación, servicio al cliente, entre otras, para aplicarse en los destinos (Sectur, 2020b).

\section{Medidas sobre cuidado de la salud y apoyo a las personas}

Se creó la aplicación COVID-19MX con el fin de contribuir al conocimiento de las medidas de prevención y el intercambio de información entre funcionarios y ciudadanos. El 23 de marzo se establecieron los criterios en materia de administración de recursos humanos para contener la propagación, permitiendo: a) trabajo en casa para adultos mayores, personas con discapacidad, mujeres embarazadas y personas con enfermedades crónicas, b) días laborales alternados, c) horarios escalonados, publicados en el Diario Oficial de la Federación (DOF, 2020a). El 7 de abril se anunció la compra de equipo médico, mediante gestiones con el gobierno chino.

El 13 de abril se firmó el acuerdo Todos juntos contra el COVID-19, que involucró a 146 hospitales privados de 27 estados, a través del cual el gobierno podrá hacer uso del $50 \%$ de la capacidad en camas para enfermos del COVID-19. Asimismo, el Servicio de Administración Tributaria (SAT) ofreció una extensión en el plazo para presentar la declaración de impuestos. El Instituto del Fondo Nacional de la Vivienda para los Trabajadores (Infonavit) dio a conocer protocolos para beneficiar a las 
empresas de hasta 250 empleados, a fin de diferir el aporte a la vivienda; además, anunció que, en caso de desempleo, se cubrirán de uno a tres meses de pagos, con derecho a extensión hasta por seis meses (OCDE, 2020).

\section{Medidas fiscales}

Se asigna el 24 de marzo un presupuesto extraordinario de 4 mil millones de pesos al Ejército y la Marina, con el propósito de reforzar el Plan DN-III en respuesta a la emergencia del COVID. Se autorizan 4.5 mil millones de pesos al Instituto de Salud para el Bienestar (Insabi) destinados a la compra de insumos médicos, medicamentos y equipo; además, los Estados, a través de este organismo, recibirán transferencias de hasta 10 mil millones de fondo anticipado (OCDE, 2020).

\section{Monetaria y regulación}

El 25 de marzo, la Asociación de Bancos de México anunció diferimiento parcial o total de pagos de capital o intereses hasta por cuatro meses (Cota et al., 2020), AC Banxico redujo su tasa de interés de referencia en tres ocasiones al 25 de abril; además, estableció temporalmente con la Reserva Federal de Estados Unidos (FED) una línea de intercambio de dólares por 60 mil millones y redujo en 50 mil millones de pesos el monto del Depósito de Regulación Monetaria (DRM), con el objeto de mejorar el flujo y capacidad de otorgar créditos. De igual manera el 21 de abril se aprobaron 10 medidas adicionales para asegurar la liquidez en pesos y la optimización del funcionamiento del mercado interno, con énfasis en los canales de crédito y el mercado de deudas y divisas (OCDE, 2020, p. 38).

\section{Medidas para estimular los diferentes sectores}

El gobierno federal, a través de Nacional Financiera (NAFIN) y con el fin de apoyar a las Pymes, puso a disposición créditos, además de préstamos a la economía informal (OCDE, 2020).

\subsection{Análisis de las políticas implementadas}

Se enlistaron las acciones por cada ámbito y se contrastaron con los indicadores propuestos por la CEPAL (2011) mediante un tablero semáforo, el cual nos permite visualizar por colores, significando en rojo los que se consideraron No aceptable, amarillo como Regularmente aceptable y verde Aceptable. 
Tabla 2. Acciones de políticas del gobierno federal versus indicadores de políticas públicas

\begin{tabular}{|c|c|c|c|c|c|c|c|c|}
\hline \multirow{3}{*}{ Áreas } & \multirow{3}{*}{ Número de acciones } & \multicolumn{7}{|c|}{ Indicadores: } \\
\hline & & \multicolumn{7}{|c|}{ Regular Mala ? Se desconoce } \\
\hline & & Cantidad & Calidad & Costos & Eficiencia & Tiempo & Suficiencia & Efectividad \\
\hline \multirow{7}{*}{$\begin{array}{l}\text { Contención } \\
\text { de la } \\
\text { pandemia }\end{array}$} & $\begin{array}{l}\text { 1. Suspensión de } \\
\text { actividades educativas }\end{array}$ & & & & & & & ? \\
\hline & $\begin{array}{l}\text { 2. Trabajo en casa } \\
\text { y descanso a empleados } \\
\text { vulnerables }\end{array}$ & & & & & & & ? \\
\hline & $\begin{array}{l}\text { 3. Jornada de sana } \\
\text { distancia }\end{array}$ & & & & & & & ? \\
\hline & $\begin{array}{l}\text { 4. Suspensión de } \\
\text { actividades no esenciales }\end{array}$ & & & & & & & ? \\
\hline & 5. Instalación del semáforo & & & & & & & \\
\hline & $\begin{array}{l}\text { 6. Reapertura } \\
\text { de municipios }\end{array}$ & & & & & & & ? \\
\hline & $\begin{array}{l}\text { 7. Elaboración de } \\
\text { protocolos }\end{array}$ & & & & ? & & & ? \\
\hline \multirow{4}{*}{$\begin{array}{l}\text { Sector } \\
\text { turístico }\end{array}$} & $\begin{array}{l}\text { 1. No restricción al tránsito } \\
\text { de ciudadanos extranjeros }\end{array}$ & & & & & ? & ? & ? \\
\hline & $\begin{array}{l}\text { 2. Implementación } \\
\text { de la estrategia digital }\end{array}$ & & & $?$ & ? & & & ? \\
\hline & $\begin{array}{l}\text { 3. Protocolos para hoteles } \\
\text { y restaurantes }\end{array}$ & & & & & & & ? \\
\hline & $\begin{array}{l}\text { 4. Lineamientos } \\
\text { para la reapertura }\end{array}$ & & & & ? & & & ? \\
\hline \multirow{6}{*}{$\begin{array}{l}\text { Cuidado } \\
\text { de la salud } \\
\text { y apoyo a las } \\
\text { personas }\end{array}$} & $\begin{array}{l}\text { 1. Información a través } \\
\text { de aplicación COVID-19 }\end{array}$ & & & ? & & & & ? \\
\hline & 2. Trabajo en casa & & & & $?$ & & & $?$ \\
\hline & $\begin{array}{l}\text { 3. Compra de equipo } \\
\text { médico }\end{array}$ & & & ? & ? & & & ? \\
\hline & 4. Acuerdo con hospitales & & & & & & & $?$ \\
\hline & $\begin{array}{l}\text { 5. Extensión del plazo para } \\
\text { declaración de impuestos }\end{array}$ & & & & & & & ? \\
\hline & $\begin{array}{l}\text { 6. Diferir pagos } \\
\text { del Infonavit }\end{array}$ & & & & & & & ? \\
\hline $\begin{array}{l}\text { Medidas } \\
\text { fiscales }\end{array}$ & $\begin{array}{l}\text { 1. Asignación } \\
\text { de presupuesto } \\
\text { extraordinario al ejército, } \\
\text { marina y sector salud }\end{array}$ & & & & & & & ? \\
\hline \multirow{2}{*}{$\begin{array}{l}\text { Monetaria } \\
\text { y regulación }\end{array}$} & $\begin{array}{l}\text { 1. Reducción de tasas } \\
\text { de interés }\end{array}$ & & & & & & & ? \\
\hline & $\begin{array}{l}\text { 2. Línea temporal } \\
\text { de intercambio de dólares }\end{array}$ & & & & & & & ? \\
\hline
\end{tabular}

Fuente: Elaboración propia. 


\section{Discusión}

Dado que se está en las dos primeras etapas de intervención, de acuerdo con la propuesta realizada por la CEPAL (2011), será difícil emitir juicios de valor; sin embargo, sí hay posibilidades de considerar algunos elementos que arrojan luz sobre los resultados de dichas políticas.

A nivel internacional, los gobiernos (con cierto grado de incertidumbre), han implementado una serie de medidas con el propósito de frenar la pandemia. Es de señalar, con las correspondientes diferencias por país, que unos lo han hecho mejor que otros, considerando que gran parte de las decisiones que se han tomado fueron sobre la base de prueba y error.

Los esfuerzos, en su mayoría, se han centrado en la limitación de la movilidad, el aislamiento y la suspensión de actividades (exceptuando las esenciales), paquetes financieros de ayuda, fortalecimiento de sus sistemas de salud, además de realizar protocolos de higiene y limpieza, por mencionar algunos. En ese sentido, los resultados del comparativo entre las recomendaciones y la implementación de políticas muestran una clara concordancia y cercanía con las sugerencias internacionales.

\subsection{México, revisión y alcances}

Esta pandemia ha permitido visualizar y recordarnos las brechas existentes entre los países, tal como lo señala Fuentes-Nieva (2020), se muestra una divergencia en todas las dimensiones. Para México el escenario se torna complejo, al existir una fragilidad previamente asentada (Coneval, 2020), palpable en el ambiente económico y un sistema de salud precario y desigual (Fuentes-Nieva, 2020), una relación dependiente con los Estados Unidos (inversión, exportaciones y remesas) además de atrasos históricos y problemas como la baja carga tributaria, y la disminución de los ingresos por el petróleo (Blanke, 2020).

Con la dificultad del fenómeno y la insuficiencia de las medidas adoptadas, hasta ahora se han reportado 12.5 millones de personas desempleadas, de acuerdo con el Instituto Nacional de Estadística y Geografía (INEGI, 2020). Por otra parte, el Gobierno de la República emitió el 15 de mayo el documento La nueva política económica en los tiempos del coronavirus, de la cual destaca"la construcción de un nuevo modelo de país, con base en cinco principios: democracia, justicia honestidad, auste- 
ridad y bienestar, formulando la nueva política económica" (2020, p. 2), que al final de cuentas no proporciona una idea clara del camino a seguir.

Las políticas reflejadas en los programas sociales, emprendidas desde el inicio del actual gobierno (2018-2024) abarcan apoyo a pescadores, productores del campo, agricultores, adultos mayores y aprendices; sin embargo, es importante señalar que deja fuera a los trabajadores informales (Fuentes-Nieva, 2020). El 23 de abril de 2020 se establecieron 39 programas prioritarios, de los cuales 19 corresponden al ámbito social, solo dos afectan directamente el desarrollo de la actividad turística que son el número 17, Aeropuerto General Felipe Ángeles, y el 32, Tren Maya (DOF, 2020b).

Adicionalmente, se percibe un descuido de las condiciones de la clase media; flota en el ambiente una sensación de retrasos para implementar actuaciones y enfrentamiento de posturas, con mensajes contradictorios entre la Presidencia y algunos Secretarios de Estado, asimismo, notas como la publicada el día 12 de junio de 2020 donde la OMS solicita al gobierno mantener un flujo coherente de información relacionada con la pandemia del COVID-19, a través de su director ejecutivo (Televisa. NEWS, 2020), evidencian la incoherencia de algunas acciones y no abonan a un clima que facilite la recuperación.

\subsection{Sector turístico}

En lo referente a la evaluación de la política pública en el sector, es importante señalar que el grado de complejidad que contiene se encuentra en lo complicado de establecer el impacto de las acciones gubernamentales (Pereira et al., 2019). Zepeda (2018) destaca que la visión política del turismo de 1985 al 2018 ha sido concebirlo como un generador de empleos, captación de divisas, alternativa de desarrollo, factor de progreso, motor del crecimiento.

En el mismo orden de ideas, la Sectur (2014) establece que las acciones prioritarias están orientadas a incrementar el volumen de visitantes internacionales, su estancia y gasto promedio. Sin embargo, en este periodo aún no queda claro el rumbo y políticas del sector. No obstante, realmente podría resultar aventurado hablar de la posibilidad de dibujar algunos trazos de lo que será el nuevo panorama en el turismo, cuando aún no se contabiliza la totalidad de los daños generados. Es preciso pensar en la conjunción de acciones de tres factores como lo subraya Vargas (2020, p. 2): "la política gubernamental, el comportamiento del turista y la cultura organizacional de las empresas". 
El pasado 9 de junio, el Secretario de Turismo en México, Miguel Torruco, solicitó a las autoridades sanitarias, a los miembros del gabinete y a gobernadores de los estados considerar al sector turismo como esencial, a fin de impulsar la economía y ante la inminente pérdida de empleos (Sectur, 2020e), posiblemente este llamado fue escuchado y analizado para que se tomara la decisión de que, a partir del 15 de junio, se diera ese paso.

Como resultado de lo anterior, paulatinamente la industria se va reactivando en cada entidad del país, tomando en cuenta dos variables (situación de la pandemia y dependencia de la economía de la entidad a la actividad turística). Se estableció que se abrieran plazas y centros comerciales, playas, hoteles y otros giros, con una capacidad únicamente de entre 25 y $30 \%$ y acatando los protocolos y las medidas de prevención que supone la nueva normalidad.

\subsection{Coherencia con organismos internacionales relacionados con el sector}

Una vez revisadas las recomendaciones de los organismos internacionales, estas se centran en las actuaciones en áreas prioritarias del gobierno, siendo coherentes. Las demandas de los organismos y cámaras nacionales se encuentran en la misma sintonía que los organismos internacionales, sobre todo en el ámbito de los apoyos fiscales para las empresas turísticas.

\subsection{Posibles escenarios}

Uno de los retos consistirá en hacer posible la conjunción de la seguridad, la salud pública y la recuperación del sector (AECIT, 2020). Araújo y Toubes (2020) señalan que al reactivar el turismo podrían presentarse los siguientes comportamientos predictibles: a) fuerte movilidad, b) una urgente necesidad de imagen de limpieza, c) aversión a las aglomeraciones, d) demanda de turismo rural, e) uso del transporte privado, f) condiciones sanitarias del destino, y g) disminución de precios. Se plantean igualmente algunas posibles líneas aplicables a la industria: menos volumen, menos viajes de trabajo, nueva forma del producto (modificación del concepto), menos activos e incertidumbre permanente (Preferente.com, 2020).

Bajo este marco, y en contraste a las políticas implementadas en el sector, se puede aseverar una insuficiencia de acciones integrales para el futuro desarrollo de la actividad turística en el país. Se sigue trabajando bajo la premisa de prueba y error; ante escenarios tan inciertos, la falta de contundencia y claridad genera mayor incerti- 
dumbre. Este rompimiento o reset, como le llaman algunos autores, es la oportunidad de repensar el desarrollo del turismo en México y el mundo, tomando como base la problemática social y ambiental, así como los cambios tecnológicos para el futuro desarrollo de la industria.

Una discusión pendiente, que es todo un tema por desarrollar, es lo correspondiente a los derechos humanos, que transitan desde las formas de estigmatización y discriminación (eventos de agresión contra el personal médico y personas contagiadas), hasta la afectación de derechos por las medidas contra la propagación, el exceso y abuso de las autoridades, donde casos como el de Giovanni López y Alexander Martínez en México o George Floyd en los Estados Unidos, por mencionar algunos, salen a luz y en nada contribuyen al ambiente de por sí complejo.

\section{Conclusiones}

El presente trabajo evidencia el actuar reflejado en las políticas del gobierno, en referencia a las recomendaciones sugeridas por los diversos organismos internacionales. México se encuentra en coherencia y cercanía con estas, por lo que podría considerarse que se están emprendiendo las acciones adecuadas; sin embargo, al revisar los resultados arrojados de acuerdo con el tablero que contrasta las acciones versus los indicadores propuestos por la CEPAL (2011), en materia de cualificación de políticas públicas, se obtienen los siguientes escenarios:

- Se percibe que el mayor fracaso de las políticas implementadas al respecto es la creación del semáforo como instrumento de la situación a nivel nacional, por estado, siendo no aceptable (color rojo), en los rubros de cantidad, eficiencia, suficiencia y efectividad.

- La implementación de la estrategia digital en el indicador de suficiencia no es aceptable.

- Las acciones referentes a la instalación de la Jornada de sana distancia, la suspensión de actividades no esenciales y la no restricción al tránsito de ciudadanos extranjeros, en la parte de costos se califican como no suficientes.

- Cinco criterios se encuentran calificados medianamente aceptables (color amarillo) y otros cinco no se pueden definir. 
Por lo anterior, se puede concluir que la actuación del gobierno federal mexicano en la implementación de políticas en lo general, que afectan el desarrollo de la actividad turística en lo particular, ha sido débil y se manifiestan áreas de oportunidad abiertas para su intervención.

\section{Referencias}

Aguilar, A. y Lima, F. (2009). ¿Qué son y para qué sirven las políticas públicas? Contribuciones a las Ciencias Sociales, 5. www.eumed.net/rev/cccss/05/aalf.htm

Andreu, L., Palomo, J. y Stojanovic, I. (2020). Recuperar la confianza de los turistas: medidas a implementar por el COVID-19. En F. J. Bauzá y F. J. Melgosa (Dirs.), Turismo post COVID-19. El turismo después de la pandemia global análisis, perspectivas y vías de recuperación (pp. 2-11). Asociación Española de Expertos Científicos en Turismo. https://bit.ly/33khQV4

Araújo, N. y Toubes, D. (2020). Empresa turística: cómo afrontar la gestión después de una crisis sanitaria. En F. J. Bauzá y F. J. Melgosa (Dirs.), Turismo post COVID-19. El turismo después de la pandemia global, análisis, perspectivas y vías de recuperación (pp. 2 -14). Asociación Española de Expertos Científicos en Turismo. https://bit.ly/33khQV4

Asociación Española de Expertos Científicos en Turismo (AECIT). (2020). Turismo post COVID-19. El turismo después de la pandemia global, análisis, perspectivas y vías de recuperación. https://bit.ly/33khQV4

Bartik, A., Bertrand, M., Cullen, Z., Glaese, E., Luca, M. y Santon, C. (2020). How are small businesses adjusting to COVID-19: early evidence from a survey. NBER Working Knowledge, 26989, 20-102. https://hbs.me/2FnsPEY

British Broadcasting Corporation (BBC). (2009). El enorme costo económico del dengue. https://bbc.in/32mBOPL

Blanke, S. (2020). México: una gran crisis sin (grandes) respuestas. Nueva Sociedad, 224. http://bitly.ws/9CwN

Boyer, R. (2020, 27 de marzo). Coronavirus: cette crise inédite adresse un redoutable avertissement aux économistes. Le Monde. http://bitly.ws/9Cwy 
Cámara Nacional de la Industria de Restaurantes y Alimentos Condimentados (CANIRAC). (2020a). Protocolo de prevención COVID-19 "mesa segura". http://bitly. Ws/9CwV

Cámara Nacional de la Industria de Restaurantes y Alimentos Condimentados (CANIRAC). (2020b). Acciones para mitigar los daños en la industria y activar la economía (a causa del COVID-19). http://bitly.ws/9Cww

Castells, M. (2020, 18 de abril). Reset. La Vanguardia. http://bitly.ws/9Cwx

Centro Nacional de Programas Preventivos y Control de Enfermedades (Cenaprece). (s.f.). Plan nacional para la preparación y respuesta ante la intensificación de la influenza estacional 0 ante una pandemia de influenza. http://bitly.ws/9CwB

César, A. (2020). Sociedad, turismo y pandemia: cambio o continuidad. En F. J. Bauzá y F. J. Melgosa (Dirs.), Turismo post COVID-19. El turismo después de la pandemia global análisis, perspectivas y vías de recuperación (pp. 2-14). Asociación Española de Expertos Científicos en Turismo. https://bit.ly/33khQV4

Chappelow, J. (2019, 11 de octubre). Economic shock. Investopedia. http://bitly.ws/ $9 \mathrm{CwR}$

Comisión Económica para América Latina (CEPAL). (2011). Planificación estratégica e indicadores de desempeño en el sector público. https://bit.ly/2Zu1sjO

Comisión Económica para América Latina (CEPAL). (2020). América Latina y el Caribe ante la pandemia del COVID-19. Efectos económicos y sociales. http://bitly. ws/9CwS

Confederación Nacional de Comercio, Servicios y Turismo (Concanaco- Servytur). (2020). Promoverá los lineamientos técnicos específicos para la reapertura de las actividades económicas. https://www.concanaco.com.mx.

Consejo Nacional de Evaluación de la Política de Desarrollo Social (Coneval). (2020). La crisis sanitaria generada por la COVID-19 y sus consecuencias económicas ponen en riesgo avances en el desarrollo social y puede afectar en mayor medida a grupos vulnerables. http://bitly.ws/9CwT

Consejo Nacional Empresarial Turístico (CNET). (2020). Hasta 2024, recuperación de turismo: CNET. http://bitly.ws/9CwU

Cota, V., Reyes, I., Rosenzweig, F., Kim, J., Fernández, M., Olea, A., Hernández, D., García, S., Neyra, G., García, M. y Ruiz, V. (2020). COVID-19: impacto legal en Mé- 
xico, medidas dictadas por diversas autoridades. WHITE \& CASE. http://bitly. ws/9CwX

Diario Oficial de la Federación (DOF). (2020a, 23 de marzo). Acuerdo por el que se establecen los criterios en materia de administración de recursos humanos para contener la propagación del coronavirus COVID-19, en las dependencias y entidades de la Administración Pública Federal. http://bitly.ws/9CwZ

Diario Oficial de la Federación (DOF). (2020b, 23 de abril). Decreto por el que se establecen las medidas de austeridad que deberán observar las dependencias y entidades de la Administración Pública Federal bajo los criterios que en mismo se indican. http://bitly.ws/9Cx2

Diario Oficial de la Federación (DOF). (2020c, 29 de mayo). Acuerdo por el que se establecen los lineamientos técnicos para la reapertura de las actividades económicas. Secretaría de Salud. http://bitly.ws/9CwY

Dinarto, D., Wanto, A. y Sebastian, L. (2020). COVID-19: impact on Bintan's tourism sector, RSIS Commentary, 33. https://bit.ly/35uj6rl

Dolnicar, S. y Zare S. (2020). COVID-19 and Airbnb - Disrupting the disruptor. Annals of Tourism Research, 83. https://doi.org/10.1016/j.annals.2020.102961

Fuentes-Nieva, R. (2020, 9 de abril). México y el coronavirus: pasividad gubernamental en una sociedad desigual. Análisis Carolina. http://bitly.ws/9Cx3

Funes, L. (2011). Manual-Guía de formación de formadores: Salud y turismo para Centroamérica y República Dominicana. Organización Panamericana de la Salud, Consejo Centroamericano de Turismo. https://bit.ly/35oUzUL

García, B., Carranco, Z. y Martínez-Lazcano, E. (2009). El sector turístico mexicano frente a la crisis internacional. El Cotidiano, 157, 101-107. https://bit.ly/32ntlvB

Global Web Index. (2020). Coronavirus: Insights from wave 4 of our multinational study. http://bitly.ws/9Cxo

Gössling, S., Scott D. y Hall, M. (2020). Pandemics, tourism and global change: A rapid assessment of COVID-19. Journal of Sustainable Tourism, https://doi.org/10 $.1080 / 09669582.2020 .1758708$

Grupo Banco Mundial (GBM). (2020). Apoyo para 100 países en respuesta a la COVID-19 (coronavirus). http://bitly.ws/9Cxp 
Guardia, F. (2020). Impacto de las enfermedades en la economía global. EY. http:// bitly.ws/9Cxs

Instituto Nacional de Estadística y Geografía (INEGI). (2015) Censos económicos 2014. https://www.inegi.org.mx/programas/ce/2014/

Instituto Nacional de Estadística y Geografía (INEGI). (2020). Encuesta telefónica de ocupación y empleo (ETOE). http://bitly.ws/9Cxt

Madrid, F. (2020). Estimación del impacto a la actividad turística en México por la COVID-19 en el mes de abril de 2020, del dato al relato en turismo. Centro de Investigaciones y Competitividad Turística Anáhuac. https://bit.ly/33fmPq4

Niewiadomski, P. (2020). COVID-19: from temporary de-globalization to a re-discovery of tourism? Tourism Geographies. https://doi.org/10.1080/14616688.202 0.1757749

Nissen, M. y Rivas, J. (2020). The Coronavirus (COVID-19) pandemic has been declared an exceptional occurrence, paving the way for more and faster approval of national State aid initiatives in the EU. Bird \& Bird. http://bitly.ws/ 9Cxy

Organización de Aviación Civil Internacional (OACI). (2020). El Consejo de la OACI adopta una declaración sobre la COVID-19. http://bitly.ws/9CxC

Organización Mundial de la Salud (OMS). (2005) Global public health:Major challenges. http://bitly.ws/9CxD

Organización Mundial de la Salud (OMS). (2020a). Consejos de la OMS sobre viajes internacionales y comercio en relación con el brote de neumonía causado por un nuevo coronavirus en China. https://bit.ly/3idsKSR

Organización Mundial de la Salud (OMS). (2020b). Actualización de la estrategia frente a la COVID-19. http://bitly.ws/9CxE

Organización Mundial del Turismo (OMT). (2020a). COVID-19 related travel restrictions a global review for tourism second report. http://bitly.ws/9CxI

Organización Mundial del Turismo (OMT). (2020b). Apoyo al empleo y a la economía a través de los viajes y el turismo; llamamiento a la acción para mitigar el impacto socioeconómico de la COVID-19y acelerar la recuperación. http://bitly.ws/9CxM

Organización Mundial del Turismo (OMT). (2020c). Leading global protocols for the new normal. http://bitly.ws/9CxV 
Organización Panamericana de la Salud (OPS). (2010). Evaluación preliminar del impacto en México de la influenza AH1N1. Comisión Económica para América Latina, Organización Panamericana de la Salud y Organización Mundial de la Salud. http://bitly.ws/9CyR

Organización Panamericana de la Salud (OPS). (2015). Actualización epidemiológica del Síndrome respiratorio por coronavirus del Medio Oriente (MERS-CoV). http://bitly.ws/9CyL

Organización Panamericana de la Salud (OPS). (2020). La OMS caracteriza a COVID-19 como una pandemia. http://bitly.ws/9CyJ

Organización para la Cooperación y el Desarrollo Económico (OCDE). (2020). Monitoreo de las políticas por país: México. http://bitly.ws/9CyG

Pereira, G., Pinto, D., De Souza, S. y Pires, M. (2019). Evaluación de la política pública para el desarrollo del turismo: el uso del método de las diferencias en diferencias. Estudios y Perspectivas en Turismo, 28, 149-166.

Preferente.com. (2020). Las 5 claves del nuevo turismo tras el coronavirus. http://bitly. ws/9CyF

Gobierno de la República. (2020). La nueva política económica en los tiempos de coronavirus. http://bitly.ws/9CyE

Programas de las Naciones Unidas para el Desarrollo (PNUD). (2017). Evaluación del impacto socioeconómico del virus del zika en América Latina y el Caribe: Brasil, Colombia y Surinam como estudio de caso. http://bitly.ws/9CyD

Quiroz, J. (2019, 23 de abril). A 10 años del brote de influenza, el turismo busca más promoción. La Jornada. http://bitly.ws/9CyA

Rider, G. (2020). EI COVID-19 ha revelado la fragilidad de nuestras economías. Organización Mundial del Trabajo. http://bitly.ws/9Cyz

Romero, Y., Romero, J. y Navarro E. (2020). Reflexiones desde el post-crecimiento: ideas, estrategias y tácticas para el turismo post-COVID-19. En F. J. Bauzá y F. J. Melgosa (directores), Turismo post COVID-19. El turismo después de la pandemia global, análisis, perspectivas y vías de recuperación (pp. 2 -14) Asociación Española de Expertos Científicos en Turismo. https://bit.ly/33khQV4

Secretaría de Turismo (Sectur). (2014). Evaluación de desempeño de los destinos turísticos en el marco de los convenios de coordinación en materia de reasignación 
de recursos (CCRR). Análisis del desempeño turístico local: Modelo de satisfacción de los turistas. http://bitly.ws/9Cyx

Secretaría de Turismo (Sectur). (2020a). Escenarios 2020, COVID-19 (marzo 2020).

Secretaría de Turismo (Sectur). (2020b). Lineamiento nacional para la reapertura del sector turístico. http://bitly.ws/9Cyu

Secretaría de Turismo (Sectur). (2020c). Actualización del protocolo para personas, centros de hospedaje y restaurantes durante la cuarentena obligatoria por COVID-19. http://bitly.ws/9Cyo

Secretaría de Turismo (Sectur). (2020d). Presenta Miguel Torruco la estrategia digital para la contención de crisis del sector turístico. http://bitly.ws/9Cyh

Secretaría de Turismo (Sectur). (2020e). Analiza el Gobierno Federal declarar al turismo actividad esencial. http://bitly.ws/9Cyg

Sistema Económico Latinoamericano y del Caribe (SELA). (2020). COVID-19: Resumen de las principales medidas, acciones y políticas; implementados por los Estados miembros del SELA. http://bitly.ws/9Cyd

Strielkowski, W. (2020). COVID-19 recovery strategy for tourism industry. Centre for Tourism Studies. https://doi.org/10.13140 / RG.2.2.19039.8208

Televisa.NEWS. (2020, 12 de junio). OMS pide a México dar "mensajes coherentes" ante pandemia de COVID-19. http://bitly.ws/9Cy6

Vargas, A. (2020). Entender el turismo post-coronavirus: posibles escenarios. En F. J. Bauzá y F. J. Melgosa (directores), Turismo post COVID-19. El turismo después de la pandemia global análisis, perspectivas y vías de recuperación (pp. 2 -14). Asociación Española de Expertos Científicos en Turismo. https://bit.ly/33khQV4

World Travel \& Tourism Council (WTTC). (2020). Vidas devastadas y un millón de empleos por día perdidos debido a la pandemia de coronavirus. http://bitly.ws/9Cy4

Yang, Y. Zhang, H. y Chen, X. (2020). Coronavirus pandemic and tourism: dynamic stochastic general equilibrium modeling of infectious disease outbreak. Annals of Tourism Research. https://doi.org/10.1016/j.annals.2020.102913

Zepeda, A., Medina, J. y Pérez, E. (2018). Aproximación a las políticas públicas al respecto del desarrollo sostenible del año 1985 a 2015 a través de los planes de desarrollo de México en materia turística. En M. A. Burne y A. Gómez (Coords.), El turismo frente a los Objetivos del Desarrollo Sustentable (pp. 297212). Universidad de Guadalajara. 